\title{
"THE OVERALL AIM OF THIS WORK IS ...." FUNCTIONAL ANALYSIS OF GRAMMATICAL SUBJECT IN RESEARCH ARTICLE INTRODUCTIONS ACROSS FOUR DISCIPLINES
}

\author{
Seyed Foad Ebrahimi
}

\begin{abstract}
This study investigates the types and discourse functions of grammatical subjects in research article introductions across four disciplines, namely: Applied Linguistics and Psychology, representing soft sciences, and Chemistry and Environmental Engineering, representing hard sciences. This study was carried out on a corpus of 40 research article introductions (10 from each discipline). The research article introductions were sourced from twelve ISI journals published from 2008 to 2012. The corpus was analysed based on the modified model in relation to grammatical subject types and discourse functions suggested by Ebrahimi (2014). The results revealed that the grammatical subject type selections were guided by the nature of the research article introduction. However, the frequency of use of the grammatical subject types was constrained by the nature of the discipline. Discourse functions of grammatical subject types were predominantly determined by the divisions of the hard and soft sciences, and the specific disciplines within and the internal structure of the research article introductions. In addition, the results of this study manifest a new framework for the analysis of discourse functions of grammatical subject types in research article introductions.
\end{abstract}

\section{Keywords}

grammatical subject, discourse function, disciplinary difference, research article introduction

\section{Introduction}

In recent decades, academic writing has attracted the interest of numerous researchers. Many of these researchers have devoted their concentration to the genre of research articles (henceforth RA) and its sections of introduction, method, results and discussion (IMRD). Among the RA sections, the introduction has received the greatest attention from researchers. This attention gives research article introductions (henceforth RAI) great potential for textual investigation. The RAI is the anchor point after the title and is written to provide readers with information concerning the research background, rationale, gap, objectives, delimitations and assumptions (Jalilifar 2009). The RAI is quite a challenging section since writers in this section "project themselves for the first time and they 
prepare the ground for the research to come by referring to previous research and emphasising possible existing gap in the literature" (del Saz Rubio 2011: 259). According to Swales (1990: 142), the significance of the RAI is rooted in attending to "the need to re-establish in the eyes of the discourse community the significance of the research field itself; the need to 'situate' the actual research in terms of that significance; and the need to show how this niche in the wider ecosystem will be occupied and defended". Lim (2012) states that the significance of the RAI descends from the fact that writers need to present a convincing, valid and remarkable introduction to guarantee capturing the interest of the audience, especially of peer researchers and reviewers.

In the last two decades, a number of researchers have studied RAIs from one or more disciplines for rhetorical structure and/or linguistic features (Gledhill 2000, Samraj 2002, Fakhri 2004, Ozturk 2007, Hirano 2009, Loi \& Evans 2010, Sheldon 2011, Martín \& Perez 2014). Gledhill (2000) studied the discourse functions of collocations in Medical RAIs. Samraj (2002) analysed RAIs from two related disciplines of Wildlife Behaviour and Conservation Biology for their rhetorical structures. Fakhri (2004) investigated the rhetorical properties of Arabic RAIs, using Swales' CARS model. Ozturk (2007) explored the degree of variation in the rhetorical structure of Applied Linguistics RAIs. Hirano (2009) compared the rhetorical structure of RAIs in Brazilian Portuguese and English within a subfield of Applied Linguistics. Loi and Evans (2010) investigated the rhetorical structure of RAI sections of English and Chinese RAs in the field of Educational Psychology. Sheldon (2011) studied the rhetorical structure of English and Spanish RAIs, as well as RAIs written in English by Spanish-background speakers in the field of applied linguistics. Martín and Perez (2014) examined comparatively the rhetorical structure of RAIs written in English and Spanish in four disciplines in the fields of Health Sciences and Humanities/Social Sciences. The reviewed literature clearly indicates that the RAI section was mostly studied for its rhetorical structure and the linguistic features received little attention. One of the important linguistic features in academic writing is grammatical subject (GS). Two of the latest studies on the discourse functions of GS are carried out by Saadabadi and Ebrahimi (2014) and Ebrahimi and Chan (2015). Saadabadi and Ebrahimi (2014) studied the use and discourse functions of GS in RA abstracts from the two disciplines of Economics and Biology. They analysed 50 abstracts and found that there were disciplinary differences in relation to the use of the research-related entity, research-related event, self-mention, and introducing some of the study's grammatical subjects. They also reported that, mostly, the GSs were used to serve similar discourse functions in both sets of abstracts. Ebrahimi and Chan (2015) investigated the discourse functions of GSs in RA 
abstracts from two disciplines, namely Applied Linguistics and Economics. They analyzed 60 research article abstracts (30 from each discipline) using the classification of discourse functions of GSs suggested by Gosden (1993). They reported disciplinary differences and showed how the writers map and balance the demonstration of these four domains in their RA abstracts. Their findings stress the claim that "academic writing is shaped by the writer's disciplinary background" (Ebrahimi \& Chan 2015: 70) with particular reference to the use of the GS in text development. Thus, the above literature motivated this study to investigate RAIs from four disciplines, namely Applied Linguistics, Psychology, Chemistry and Environmental Engineering for the manifestation and discourse functions of GS. More specifically, to meet the aim of this study, four questions were put forward:

1. What are the types of GS used in the RAIs in the four disciplines?

2. What are the discourse functions performed by the types of GS used in the RAIs from the four disciplines?

3. Are there similarities or differences between the RAIs from the four disciplines with regard to the GS types?

4. Are there similarities or differences between the RAIs from the four disciplines with regard to the discourse functions of GS types?

\section{Methodology}

\subsection{Design and corpus}

In this study, a mixed qualitative and quantitative design is used. At one extreme, the quantitative analysis gives information regarding the frequency of GS types used in the RAIs across the four disciplines. At the other extreme, the qualitative analysis presents the discourse functions of the applied GSs and provides the possible explanations for their use.

\subsection{Corpus compilation}

This study was carried out on a corpus of 40 introduction sections of RAs sourced from high-stack international leading journals published by Elsevier during the five years from 2008 to 2012. All the selected journals are indexed in ISI. All RAs were from four disciplines, namely Applied Linguistics (AL), Psychology (Psy), Environmental Engineering (EE) and Chemistry (Che). The selected disciplines were considered based on the two broad domains of knowledge categorised by Becher (1989), soft and hard sciences. 


\subsection{Analytical framework}

The corpus was analysed based on the modified model of the available models in relation to GS types and discourse functions suggested by Ebrahimi (2014). The details of the framework are presented in Table 1.

\begin{tabular}{|c|c|}
\hline Types of GS & Discourse function and example \\
\hline \multirow{2}{*}{$\begin{array}{r}\text { Research- } \\
\text { related } \\
\text { object }\end{array}$} & $\begin{array}{l}\text { Function: To present materials, entities and objects concerned with the physical } \\
\text { world. }\end{array}$ \\
\hline & $\begin{array}{l}\text { Example: The three disciplines were selected as examples of the sciences } \\
\text { (biology), social sciences (linguistics) and humanities (philosophy). (AL 2) }\end{array}$ \\
\hline \multirow{2}{*}{$\begin{array}{r}\text { Research- } \\
\text { related } \\
\text { process }\end{array}$} & $\begin{array}{l}\text { Function: To present actions and procedures executed in or resulting from } \\
\text { scientific research activities. }\end{array}$ \\
\hline & $\begin{array}{l}\text { Example: A movement awav from the target is seen as avoidance behaviour, with } \\
\text { negative valence. (Psy } 1 \text { ) }\end{array}$ \\
\hline \multirow{2}{*}{$\begin{array}{l}\text { Introducing } \\
\text { (part) of the } \\
\text { study }\end{array}$} & Function: To refer to integral parts or internal entities of a discourse. \\
\hline & $\begin{array}{l}\text { Example: The purpose of this paper is to present a generic description of } \\
\text { discursive practices in law as they emerge from two different international } \\
\text { academic and professional contexts of written communication. (AL 7) } \\
\text { Example: This paper reports on a study of master's theses from a cross- } \\
\text { disciplinary perspective using both textual and interview data. (AL 2) }\end{array}$ \\
\hline \multirow[t]{2}{*}{$\begin{array}{r}\text { Personal } \\
\text { citation }\end{array}$} & $\begin{array}{l}\text { Function: To refer to earlier researches by citing the authors' names of earlier } \\
\text { studies. }\end{array}$ \\
\hline & $\begin{array}{l}\text { Example: Ryalls et al. (1997) reported that females produced longer positive } \\
\text { VOTs for voiceless plosives and smaller negative VOTs for voiced plosives. } \\
\text { (AL 1) }\end{array}$ \\
\hline \multirow[t]{2}{*}{$\begin{array}{r}\text { Impersonal } \\
\text { citation }\end{array}$} & $\begin{array}{l}\text { Function: To refer to earlier researches by citing the community-validated } \\
\text { studies. }\end{array}$ \\
\hline & $\begin{array}{l}\text { Example: Studies suggest that perfectionism may be important in social anxiety } \\
\text { disorder. (Psy 4) }\end{array}$ \\
\hline \multirow[t]{2}{*}{$\begin{array}{r}\text { Self- } \\
\text { mention }\end{array}$} & $\begin{array}{l}\text { Function: To clearly present the author(s) and mostly recognized through the use } \\
\text { of 'we', even in the case where there is a single named author. }\end{array}$ \\
\hline & $\begin{array}{l}\text { Example: We perceive speech sounds categorically - that is to say, we are more } \\
\text { likely to notice the differences between categories than within categories. (AL 5) }\end{array}$ \\
\hline
\end{tabular}


“The Overall Aim of This Work is ...." Functional Analysis of Grammatical Subject in Research Article Introductions Across Four Disciplines

\begin{tabular}{|c|c|}
\hline Types of GS & Discourse function and example \\
\hline \multirow[t]{2}{*}{ This } & Function: The GS is clearly recognized through the use of 'this'. \\
\hline & $\begin{array}{l}\text { Example: This results in the INTRODUCTION and BODY sections of Opinions } \\
\text { to be less than concise and focused statement of the relevant law, and therefore } \\
\text { leads Italian writers to give their Opinions a feel of a legal Essay. (AL 7) }\end{array}$ \\
\hline \multirow[t]{2}{*}{$\begin{array}{l}\text { Empty } \\
\text { Theme }\end{array}$} & $\begin{array}{l}\text { Function: To postpone research-related entities and events characterized by } \\
\text { seemingly formulaic patterns. }\end{array}$ \\
\hline & $\begin{array}{l}\text { Example: However, it appears that the IAP might be an even more promising } \\
\text { instrument than the IAT. (Psy 1) }\end{array}$ \\
\hline
\end{tabular}

Table 1: Types and discourse functions of GS

\subsection{Procedures}

First, following Becher $(1989,1994)$, four disciplines representing hard and soft sciences were selected. Second, three journals from each discipline published by Elsevier Publication were chosen. Third, ten RAIs from ten empirical RAs published in 2008 to 2012 issues of the journals were randomly chosen. In this step, the selected RAs were written following an IMRD structure. Fourth, the researcher read all 40 RAIs to analyse them for the types and discourse functions of the used GSs. In this step, inter-rater agreement has been applied. The three raters are all experts in Applied Linguistics, who have some publications in the same or related areas. Finally, the results were tabulated and discussed.

\section{Results and discussion}

A topical unmarked theme is also referred to as a grammatical subject (GS), which can be mapped directly onto the subject position. The GS types found in RAIs were research-related object, research-related process, personal citation, impersonal citation, empty theme, introducing (part) of a study and self-mention. In this subsection, the results obtained concerning the frequency and discourse functions of these subtypes are also presented and discussed across the four disciplines and two science types.

\subsection{Research-related object}

The four sets of RAIs were analysed for their employment of research-related object GSs and the results are presented in Table 2. Based on the results, this GS was the predominant one in the four sets of RAIs. This high proportion might not be uncommon, since the writers of RAIs need to refer to the objects on which a study is based and introduce them, and report some earlier arguments stated in 
relation to these objects. This helps to claim the centrality of a study and meets one of the obligatory requirements of writing an RAI, following Swales' (1990) CARS model. In addition to the predominance of this GS in the four sets of RAIs, the result depicts a clear disciplinary difference in this regard. As is evident in Table 2, the employment of this GS ranges from 42 per cent in EE RAIs to 56 per cent in Che RAIs. This finding might tell us that Che writers are more inclined to write RAIs that are topic-based. It seems that these writers prefer to situate the research-related objects in the GS spot rather than to elaborate on them more in order to provide the readers with clear information in respect of the objects examined in a study. This in turn contributes to a better understanding of the RAI and the whole RA.

Research-related object GSs are used across the four sets of RAIs to serve the discourse function of indicating the importance of a study (Examples 1-4). Being frequent across the four disciplines in the RAIs, the obtained GSs are not surprising as in RAIs writers seek to make a claim for the centrality of their study. This is supported by Swales' (1990) CARS model. Another justification for this discourse function derives from the fact that writers need to show explicitly the importance of their study in order to persuade journal editors to publish and disciplinary community members to read them. Such introductory information at the beginning of an RAI acts as an attention-catcher to highlight the importance of a study. This discourse function helps writers to claim importance for their study by a) showing that the general area of study is important and b) reviewing earlier arguments related to the research object(s).

(1) Research article abstracts (RA abstracts) have become a well-established genre in academic discourse since Eija Ventola's (1994) plea for a linguistic approach to the genre that was capable of combining a global structural view of the genre with a prescriptive local view of the linguistic realisation of the abstract. (AL 6)

(2) However, trauma can result in a shift away from VAM towards SAM processing. (Psy 3)

(3) EPXMA is capable of simultaneously detecting the elemental composition, morphology and size of micrometer-size individual particles. (Che 4)

(4) Membrane processes are increasingly used in the environment protection, drinking-water production and medical applications. (EE 3)

From Table 2, it can be inferred that hard science writers dedicate a greater portion of theme positions to realising the research-related object GSs compared to their counterparts in soft science. This might be attributed to the objective 
nature of hard science studies, which imposes on writers the need to define and clearly state the object(s) used when carrying out an experiment. Such information is deemed necessary as it directly contributes to the objectivity of a study.

\begin{tabular}{|c|c|c|c|c|}
\hline & \multicolumn{2}{|c|}{ Soft sciences } & \multicolumn{2}{c|}{ Hard sciences } \\
\hline & AL & Psy & Che & EE \\
\hline Research-related object & $216(45 \%)$ & $171(43 \%)$ & $160(56 \%)$ & $125(42 \%)$ \\
\hline
\end{tabular}

Table 2: Frequency and percentage of the research-related object GS in RAIs

\begin{tabular}{|c|c|c|c|c|c|}
\hline & Discourse function & AL & Psy & Che & EE \\
\hline 1 & Indicate the importance of a study & $\checkmark$ & $\checkmark$ & $\checkmark$ & $\checkmark$ \\
\hline
\end{tabular}

Table 3: Discourse functions of the research-related object GS in RAIs

\subsection{Research-related process}

An ostensible disciplinary difference is noted from analysis of the four sets of RAIs for the realisation of the research-related process GSs (Table 4). The highest and lowest realisations were found in the EE and AL RAIs respectively. The strong disposition of EE writers could be attributed to the experiment-based nature of this discipline, whereby writers need to refer to the processes involved in carrying out an experiment. It seems that explicit presentations of these processes could contribute explicitly to the clear interpretation of an experiment.

As for the discourse function, this GS is used to serve the discourse function of indicating the importance of a study (Table 5). This discourse function was found in the four sets of RAIs (Examples 5-8). Such use could be imposed by the nature of the RAI. In RAIs, writers needed to ensure that readers, among whom are journal editors, understand the importance of a study. This importance can be shown by making reference to the importance of the research-related $\operatorname{object(s)~(as~discussed~above)~and~research-related~process(es).~The~reference~to~}$ research-related processes can be justified based on the experimental nature of the RAs analysed in this study. This discourse function may again be supported by Swales' (1990) CARS model. Swales (1990) points out that presenting the importance of a study and claiming centrality for it can help in the realisation of a step in move one, which is establishing the research territory.

(5) Focusing on these very common items seems likely to pay substantial dividends for novice learners. (AL 3) 
(6) Testing the relationship of high standards to social anxiety over and above the more obviously maladaptive aspects of perfectionism is necessary to demonstrate that the relationship found is not simply a reflection of the content of the rest of the items on a given scale. (Psy 4)

(7) However, binding can also have a significant impact on the pharmacokinetics of drugs, since albumin has a limited number of regions for high-affinity binding. (Che 1)

(8) Thus, providing away to oxidise Al particles in few minutes could be interesting at larger Cu matrix production scale. (EE 4)

As evident from the figures in Table 4, hard science writers dedicate a greater portion of their effort to realisation of the research-related process GSs compared to their counterparts in soft sciences. As stated above, the experiment-based nature of hard science studies is likely to motivate writers to use the processes adopted in a study in the GS spot to demonstrate its importance and impersonal nature. However, this was not found to be the case in soft science RAIs, as writers made fewer references to the processes adopted.

\begin{tabular}{|c|c|c|c|c|}
\hline & \multicolumn{2}{|c|}{ Soft sciences } & \multicolumn{2}{c|}{ Hard sciences } \\
\hline & AL & Psy & Che & EE \\
\hline Research-related process & $33(7 \%)$ & $50(13 \%)$ & $57(20 \%)$ & $86(29 \%)$ \\
\hline
\end{tabular}

Table 4: Frequency and percentage of the research-related process GS in RAIs

\begin{tabular}{|c|c|c|c|c|}
\hline Discourse function & AL & Psy & Che & EE \\
\hline Indicate the importance of a study & $\checkmark$ & $\checkmark$ & $\checkmark$ & $\checkmark$ \\
\hline
\end{tabular}

Table 5: Discourse functions of the research-related process GS in RAIs

\subsection{Personal citation}

The figures in Table 6 show a noticeable disciplinary difference concerning the use of personal citation. AL writers show the highest disposition by including a personal citation in 71 GS positions, making up 15 per cent of the total GSs. Che writers showed the least inclination by dedicating only four per cent of the total GS positions to the manifestation of personal citation. These findings indicate that when constructing an RAI, AL writers favour a) to locate their study within the existing disciplinary framework of knowledge, b) to summarise the 
literature, and c) to point to a research space. The use of personal citation might also indicate that AL writers "align themselves to a particular camp and tend to cite people from there. Partly because they have been influenced by those ideas and partly because they want them to read their works" (Hyland 1999: 359). In addition, this result might be taken to mean that AL writers use personal citation as an interpersonal resource to persuade disciplinary members to accept the arguments or findings suggested. This result also might reflect AL writers having a disposition towards exchanging academic knowledge in order to "index the disciplinary community being invoked" (Hewings et al. 2010: 103).

The four sets of RAIs were analysed for the discourse functions performed by the employment of the personal citation GS and the results are displayed in Table 6 below. Presenting the author's viewpoint and/or findings was a discourse function performed by the personal citation GS in all four sets of RAIs (Examples 9-12). This discourse function enables writers to select authors and positions related to their topic, supporting claims made earlier by Petrić and Harwood (2013). This can also depict a writer's familiarity with the existing literature, related to the aims, method, findings and conclusion. This might also signal their ability to construct coherent RAIs. Being found in all four sets of RAIs, this is supported by Swales' (1990) CARS model. Swales (1990) states that when constructing an RAI, writers need to include a review of previous research conducted in the same area.

(9) Hyland (2002) shows that the disciplinary variation in self reference noted in published writing is blurred in novice student writing and concludes that the undergraduate students studied have not been socialized into the epistemological practices of their individual disciplines. (AL 2)

(10) Shafran et al. (2003) argue that clinical perfectionism can be considered excessive striving for high standards together with critical self-evaluation. (Psy 4)

(11) Sato et al. [34] have reported the use of diluted glue in the treatment of intraorbital arteriovenous malformations (AVMs) as embolic agent in transarterial embolization procedures. (Che 10)

(12) Akbari [5] found that trees could save 21-53\% of the cooling load in Californiaof this figure, the shading component is $10-35 \%$ and the balance is due to evaporative cooling. (EE 1)

Data analysis revealed that only writers in the soft science disciplines, AL and Psy, used the personal citation GS to justify their choice of topic (Examples 13-14). This could be rooted in the fact that these writers wanted to show that the topic they were investigating was closely related to the concern of 
other researchers within the discipline. This kind of citation also increases the significance of a study by supporting the choice of a topic scientifically. Such citations show the attention paid to the topic in the literature, which supports Petrić and Harwood's (2013) findings. This also helps writers to make a claim for a topic's centrality and importance to the discipline.

(13) As English is predominantly a tense language (Norman, 1988), many researchers (Heslot, 1982; Liang, 2005; Malcolm, 1987; Salager-Meyer, 1992; Zhang, 2004) have employed the ESP genre analysis or functional grammar approach in their studies on the use of tenses at move- or section-level, or in complete English medical RAs1. (AL 4)

(14) Many authors focus on multidimensional perfectionism (Dunkley et al., 2006; Frost, Marten, Lahart, \& Rosenblate, 1990; Hewitt \& Flett, 1991; Slaney, Rice, Mobley, Trippi, \& Ashby, 2001). (Psy 4)

The personal citation GS is used to serve the discourse function of defining key terms or explaining concepts from the literature. This discourse function was found to be unique to Psy RAIs (Example 15). This kind of citation, besides providing the reader with a definition to help their interpretation, also illustrates a writer's familiarity with the area of investigation (Petrić \& Harwood 2013). In this regard, Petrić and Harwood (2013) also point out that such citations are necessary for "knowledge display" (2013: 8).

The author also defines three additional qualities related to how mindfulness is practiced: (1) in a non-judgmental way, with acceptance and allowance; (2) focused in the present moment, with beginner's mind; and (3) effectively. (Psy 10)

Data analysis revealed that soft science writers used personal citation GSs more than their counterparts in hard science. Following Becher and Trowler (2001), this can distinguish the two types of science in terms of ideology and epistemology. Knowledge within the soft sciences could be described as more personal, while in the hard sciences it is viewed more impersonally and objectively. While soft science writers mostly prefer to validate their study by presenting earlier studies, hard science writers' practice leans towards stronger certainty concerning the significance and validity of their work.

\begin{tabular}{|c|c|c|c|c|}
\hline & \multicolumn{2}{|c|}{ Soft sciences } & \multicolumn{2}{c|}{ Hard sciences } \\
\hline & AL & Psy & Che & EE \\
\hline Personal citation & $71(15 \%)$ & $36(9 \%)$ & $11(4 \%)$ & $15(5 \%)$ \\
\hline
\end{tabular}

Table 6: Frequency and percentage of personal citation GS in RAI 
“The OVerall Aim of This Work is ....” Functional Analysis of Grammatical Subject in Research Article Introductions Across Four Disciplines

\begin{tabular}{|c|l|c|c|c|c|}
\hline & \multicolumn{1}{|c|}{ Discourse function } & AL & Psy & Che & EE \\
\hline $\mathbf{1}$ & Presenting author's viewpoint and/or findings & $\checkmark$ & $\checkmark$ & $\checkmark$ & $\checkmark$ \\
\hline $\mathbf{2}$ & Justifying the choice of topic & $\checkmark$ & $\checkmark$ & $*$ & $*$ \\
\hline $\mathbf{3}$ & Defining key terms or explaining concepts & $*$ & $\checkmark$ & $*$ & $*$ \\
\hline
\end{tabular}

Table 7: Discourse functions of personal citation GS in RAI

\subsection{Impersonal citation}

The four sets of RAIs were analysed for impersonal citations and the results illustrate a telling disciplinary difference. The figures in Table 8 show that AL and Che writers used this form of GS the most and the least respectively. AL writers used this kind of citation in eight per cent of total GSs. In Che RAIs, impersonal citation was used just ten times, making up only three per cent of total GSs. This disciplinary difference indicates that AL writers, along with presenting the existing literature, are more likely to promote their own research. This kind of citation also helps AL writers to signal their contribution to the discipline's existing knowledge. Using more impersonal citations shows that AL writers, compared to the other three groups of writers, showed the highest tendency to focus on the prominence of research in RAIs.

According to Table 8, this GS serves four discourse functions in the RAIs analysed. In all four sets of RAIs, impersonal citation was used to perform the discourse function of topic relevance whereby writers justify their choice of topic (Examples 16-19). This form of topic justification directly increases the chances of RA publication, since it contributes to convincing journal reviewers that a study is on the same lines as existing disciplinary literature and makes a necessary and significant contribution. It also helps to increase the readership of an RA in as much as it is based on the existing discipline's literature. By using this kind of citation, writers show that their study was conducted to meet a need felt in the existing literature; therefore, they free themselves from taking responsibility for the study.

(16) Studies have also been conducted on the use of personal pronouns in written texts. (AL 4)

(17) Studies suggest that perfectionism may be important in social anxiety disorder. (Psy 4)

(18) A great deal of work has been done on modifying the intercalative ligand. (Che 2) 
(19) Over the last few years, several works were dedicated to the purification of water and effluents, containing heavy metal, with ultrafiltration assisted by complexation. (EE 3)

The four groups of researchers resorted to impersonal citation to present other research findings (Examples 20-23). This helps writers to prepare the reader for "what the consequences of the study could be" (Petric \& Harwood 2013: 11). Presenting the findings from earlier studies is an obligatory step when constructing RAIs, as advocated by Swales in his CARS model. In addition, it can help writers to compare and contrast earlier findings with each other. Such comparing and contrasting, according to Ghadessy (1999), gives greater credibility to a study, thus making it more meaningful. This discourse function also indicates a writer's ability to select relevant findings from among the existing literature, thus revealing their knowledge of the topic and their ability to construct a coherent argumentative RAI (Petric \& Harwood 2013).

(20) Some recent studies have also revealed disciplinary and cross-linguistic variations within this genre (e.g. Ahmad, 1997; Hyland, 2000, 2001, 2002; Mauranen, 1993; Samraj, 2002a). (AL 2)

(21) Both studies confirm the results of research relying on adult samples in that they support the idea that disgust sensitivity is involved in small-animal phobias. (Psy 2)

(22) The results showed that the degradation process occurs by attack of the ester groups spread all along the copolymer backbone. (Che 7)

(23) The results show that 2, 4-D induces toxicity which affects energy metabolism, morphological perturbation and oxidative stress. (EE 5)

Evaluating earlier studies is another discourse function performed by using impersonal citation. This discourse function was found in the AL, Psy and EE RAIs (Examples 24-26). It was mostly used to a) indicate a gap in the existing literature, or b) to present the writer's stance in relation to earlier findings. It also overtly indicates the writer's thorough knowledge of the existing disciplinary literature. This form of citation can help to convince the readers to accept the claims made by the writer in the RAI section and other sections of the RA.

(24) In this particular area of titleology, literature is not only vast and rich but also varied from the point of view of study designs (Goodman et al., 2001), topics analyzed (Berkenkotter \& Huckin, 1995; Fortanet, Coll, Palmer, \& Posteguillo, 1997; Fortanet Gómez, Posteguillo Gómez, Coll García, \& Palmer Silveira, 1998; Haggan, 2004; Laurence, 2001; Whissell, 1999), size of databases examined 
(Laurence, 2001), outcoming applications (Goodman et al., 2001; Huth, 1987), and genres considered (Dudley-Evans, 1984; Hamp-Lyons, 1987; Soler, 2007; Yakhontova, 2002). (AL 8)

(25) Admittedly, most of the studies in this research area have been correlation and so it remains unclear whether disgust is a vulnerability factor for developing anxiety problems just a by-product of anxious psychopathology. (Psy 2)

(26) Most of the available studies on vegetation influence have been carried out in temperate and desert climates, focusing on medium and low-density environments. (EE 1)

Unique to the Che RAIs, this form of citation was used to acknowledge earlier studies conducted in the area under investigation (Example 27). Such citation demonstrates a writer's thorough knowledge of the existing literature and their ability to distinguish and acknowledge the studies that have made the greatest contribution. It acts as a signpost a) to take the reader's attention to important studies in the existing literature, and b) to justify the significance of a study by linking it to the most significant ones in the literature.

Such theoretical studies on the level of molecular electronic structures of the complexes are also very significant in understanding the trend in DNA-binding and related properties of the complexes and thus guiding functional molecular design or molecular modification. (Che 2)

As with personal citation, impersonal citation was also found to be more frequent in soft science RAIs compared to hard science ones. In line with Becher and Towler's (2001) argument, this might depict an ideological and epistemological difference between the soft and hard sciences, suggesting that soft science studies need to cite earlier studies more to validate and mitigate their subjectivity.

\begin{tabular}{|c|c|c|c|c|}
\hline & \multicolumn{2}{|c|}{ Soft sciences } & \multicolumn{2}{c|}{ Hard sciences } \\
\hline & AL & Psy & Che & EE \\
\hline Impersonal citation & $39(8 \%)$ & $24(6 \%)$ & $10(3 \%)$ & $16(5 \%)$ \\
\hline
\end{tabular}

Table 8: Frequency and percentage of impersonal citation GS in RAIs 


\begin{tabular}{|c|l|c|c|c|c|}
\hline & \multicolumn{1}{|c|}{ Discourse function } & AL & Psy & Che & EE \\
\hline $\mathbf{1}$ & $\begin{array}{l}\text { Reference to topic relevance whereby } \\
\text { the writer justifies their choice of topic }\end{array}$ & $\checkmark$ & $\checkmark$ & $\checkmark$ & $\checkmark$ \\
\hline $\mathbf{2}$ & Present other research's findings & $\checkmark$ & $\checkmark$ & $\checkmark$ & $\checkmark$ \\
\hline $\mathbf{3}$ & Evaluate earlier studies & $\checkmark$ & $\checkmark$ & $*$ & $\checkmark$ \\
\hline $\mathbf{4}$ & Acknowledge earlier studies & $*$ & $*$ & $\checkmark$ & $*$ \\
\hline
\end{tabular}

Table 9: Discourse functions of impersonal citation GS in RAIs

\subsection{Empty theme}

A small disciplinary difference was found regarding application of the empty theme in the four sets of RAIs. While AL and Che writers showed the least inclination to include the empty theme, Psy and EE writers demonstrated the most use of it in constructing their RAIs (Table 10). This finding indicates that Psy and EE RAIs could be more objective and impersonal since application of the empty theme helps to deflect attention from the people engaged in a research activity and shifts the focus onto the outcome (Hewings \& Hewings 2002). As a result, longer subjects were more commonly situated at the end of a clause (Hewings \& Hewings 2002, Bloor \& Bloor 1995). This finding can be discussed based on the "information principle" (Hasselgard et al. 1998: 50), which explains a tendency in English to present relatively longer elements that carry a high load of information towards the end of a sentence. There are two other justifications for including the empty theme. First, writers might prefer to use the empty theme along with reporting verbs to gain freedom to accept, reject or remain neutral about a proposition presented (Thompson 1994). Second, writers might prefer to use the empty theme along with adjectival complementation to encode an evaluation that influences the interpretation of information presented (Hunston \& Sinclair 2000).

The results illustrate that discourse functions that are fulfilled by the empty theme are similar across the four disciplines (Table 11). The empty theme serves three discourse functions: a) making evaluative comments on earlier related studies; b) presenting earlier studies' findings; and c) indicating a gap in the existing literature.

Writers of all four sets of RAIs used the empty theme to make evaluative comments about earlier related studies (Examples 28-31). This deployment relies on the assumption that making these evaluative comments helps to convince the 
discipline and community's readers about the familiarity of the writer with the topic under investigation. It also enables writers to present their stance in relation to the existing literature and thus pave the way to explain the significance and necessity of their study. Such use of the empty theme is motivated by the nature of RAIs, in which such information constitutes an obligatory step (Swales 1990).

(28) To develop further our pedagogical descriptions of academic collocations, it will be important both to incorporate positionally-variable expressions and to provide a clear account of how well distributed items are across academic disciplines. (AL 3)

(29) However, it appears that the IAP might be an even more promising instrument than the IAT. (Psy 1)

(30) It is generally agreed that the morphology of embolic agents plays a fundamental role on the performance of the intravascular embolization procedure, since the undesirable inflammation of the embolized vessel walls and vascular recanalization, which minimizes the success of the blood vessels occlusion, are closely linked to irregular morphology of embolic agent particles. (Che 10)

(31) It appears to be the best combination of the thermal stability and electrical conductivity. (EE 4)

The results show that in all four sets of RAIs, the empty theme is used to present the results of earlier studies (Examples 32-35). As with the first discourse function, this also relates to the nature of the RAI. In an RAI, the writer needs to give a full impression of the existing literature in order to link their study to it and at the same time set the scene to present clearly the contribution of their study. Such presentation enables the writer to compare and contrast their expected results with the results of earlier studies as presented in the RAI section. According to Ghadessy (1999), this kind of comparing and contrasting increases the reliability of a study.

(32) On the negative side, it has been pointed out that backchannelling may indicate lack of interest (Schegloff, 1982, p. 85; Stenström, 1994, p. 81), and even be used to signal indignation, indifference and impatience (Stenström, 1994, p. 81). (AL 5)

(33) It was found that intrusive memories in PTSD typically consisted of sensory information, mainly images and bodily sensations. (Psy 3)

(34) It was speculated that the activity may involve GABAergic and nitroxidergic pathways. (Che 6) 
(35) It has been found that a single well placed tree with a crown of $8 \mathrm{~m}$ could reduce air conditioning usage by 2-8\% and peak cooling load demand by 2-10\%. (EE 1)

The third discourse function enacted by application of the empty theme is to indicate a gap in the existing literature (Examples 36-39). This application of the empty theme can be discussed on the grounds that writers need to indicate clearly the reasons and rationale for their study. In this case, writers must clearly point to the significance of their study in relation to the existing disciplinary literature.

(36) However, there has been, to date, no study on this common student-produced genre in the U.S. As such, a study of the master's thesis produced in U.S. universities can inform us on a student-produced genre that fills a place somewhere in between student-produced course papers, on the one hand, and published research articles, on the other, in taxonomy of academic writing. (AL 2)

(37) However, there are no studies that have investigated the differential effects of cognitive therapy (CT) on autogenous and reactive OCD patients. (Psy 5)

(38) However, to the best of our knowledge there is no other pharmacological activity that has been reported on ILNA. (Che 6)

(39) To our knowledge, there is only one paper available in the open literature dealing with the anodic oxidation of Al micrometric powder. (EE 6)

According to the figures in Table 11, the two broad divisions of science, soft and hard, pay similar attention to the use of the empty theme. This can be taken to mean that all three of the discourse functions enacted by this GS were imposed by the nature of the RAI. This similarity also suggests that all four groups of writers dealt with this kind of GS as an element that helped to express opinions, make comments and evaluate propositions in such a way that attention was deflected from the writer and allowed him or her to remain in the background (Hewings \& Hewings 2002). Hewings and Hewings (2002) emphasise that such deployment adds to the objectivity of the knowledge presented.

\begin{tabular}{|c|c|c|c|c|}
\hline & \multicolumn{2}{|c|}{ Soft sciences } & \multicolumn{2}{c|}{ Hard sciences } \\
\hline & AL & Psy & Che & EE \\
\hline Empty theme & $32(7 \%)$ & $37(9 \%)$ & $21(7 \%)$ & $25(9 \%)$ \\
\hline
\end{tabular}

Table 10: Frequency and percentage of empty theme GS in RAIs 
“The Overall Aim of This Work is ....” Functional Analysis of Grammatical Subject in Research Article Introductions Across Four Disciplines

\begin{tabular}{|l|l|c|c|c|c|}
\hline \multicolumn{1}{|c|}{ Discourse function } & AL & Psy & Che & EE \\
\hline $\mathbf{1}$ & $\begin{array}{l}\text { Making evaluative comments on } \\
\text { earlier related studies }\end{array}$ & $\checkmark$ & $\checkmark$ & $\checkmark$ & $\checkmark$ \\
\hline $\mathbf{2}$ & Presenting earlier studies' findings & $\checkmark$ & $\checkmark$ & $\checkmark$ & $\checkmark$ \\
\hline $\mathbf{3}$ & $\begin{array}{l}\text { Indicating a gap in the existing } \\
\text { literature }\end{array}$ & $\checkmark$ & $\checkmark$ & $\checkmark$ & $\checkmark$ \\
\hline
\end{tabular}

Table 11: Discourse functions of empty theme GS in RAIs

\subsection{Introducing (part) of the study}

Even though the introduction (part) of the study GS was minimally used by the four groups of writers, there is a telling disciplinary difference in this regard (Table 12). The most and the least attention given were depicted by the AL (7\%) and Che $(2 \%)$ writers, while the other two groups of writers showed a similar tendency in their use of this GS. This finding might be taken to mean that AL writers prefer to guide the reader explicitly through the different moves and steps of RAIs.

The four sets of RAIs were analysed for the discourse functions performed by the employment of this GS and the results are presented in Table 13. In all four sets of RAIs, writers used this GS to introduce the aim of the study (Examples 40-43). This can be justified on the grounds that introducing the aim of a study is an obligatory step when constructing an RAI. Writers need to state and justify their intention in conducting a study clearly in order to convince journal editors to publish and disciplinary members to read their work.

(40) This paper reports on a study of master's theses from a cross-disciplinary perspective using both textual and interview data. (AL 2)

(41) The central aim of the present study was to investigate memory elements that characterize PTSD memories (re-experiencing and disorganization) in voluntary memories of PTSD patients as well as in other populations, namely PDA patients and healthy trauma victims. (Psy 3)

(42) The overall aim of this work is the obtention of fibrillar hydrogels with controlled morphology. (Che 9)

(43) The aim of this study was to evaluate the biochemical, histopathological alterations and antioxidant status of liver rat exposed to the toxic effects of 2,4-D based herbicide "Désormone lourd". (EE 5) 
$\mathrm{AL}$ and Che writers used this GS to present the implications of their studies (Examples 44-45). This use might reflect an explicit intention on the part of writers to make a contribution via their studies to the existing literature. Such presentations of implications might explicitly guide readers' decisions regarding the relevance of an RA to their own studies or interests.

(44) This study also provides some implications for the ESP profession in legal contexts. (AL 7)

Such a study should enable one to get a better insight into such findings and into the discrimination between enzymatic and hydrolytic degradation occurring in polyesteramide chain cleavage. (Che 7)

It is worth mentioning that this GS was used to enact different discourse functions across the four sets of RAIs. AL, Psy, Che and EE writers, respectively, used it to introduce the data used (Example 46), research questions (Example 47), significance of a study (Example 48) and context of a study (Example 49). These divergent applications are not surprising given the fact that providing information about research questions, data, implications and the significance of a study are not obligatory information in RAIs. In this respect, Swales' CARS model can be seen as offering good support. These divergences, according to Hyland (2009), may be a good indication of disciplinary specificity in terms of what are considered additional elements, including meeting perceived audience needs.

(46) This paper draws its data from a larger on-going study to focus on the structure of introductions, since previous research has pointed to the rhetorical salience of this genre element in research articles (Swales, 1990; Swales \& Najjar, 1987) and dissertations (Bunton, 2002). (AL 2)

(47) Our first research question was whether an indirect measure of perceived control could predict anxiety level. (Psy 1)

(48) To the best of our knowledge, the present work illustrates for the first time the production of magnetic particles based on poly(vinyl alcohol)/poly(vinyl acetate) with core-shell type structure. (Che 10)

This study is performed in the framework of Al powder safety. (EE4)

According to the figures in Table 12, soft science writers demonstrate more use of this GS compared to their counterparts in hard sciences. This could reflect the subjective nature of soft science, which orients writers to refer to their 
studies in the GS position and keep themselves less visible and their discourse less interactional. This helps to divert the attention towards the study itself and positively contributes to the validity of a study.

\begin{tabular}{|c|c|c|c|c|}
\hline & \multicolumn{2}{|c|}{ Soft sciences } & \multicolumn{2}{c|}{ Hard sciences } \\
\hline & AL & Psy & Che & EE \\
\hline Introduction (part) to a study & $33(7 \%)$ & $14(4 \%)$ & $7(2 \%)$ & $10(4 \%)$ \\
\hline
\end{tabular}

Table 12: Frequency and percentage of introducing (part) of the study GS in RAIs

\begin{tabular}{|l|l|c|c|c|c|}
\hline & \multicolumn{1}{|c|}{ Discourse function } & AL & Psy & Che & EE \\
\hline $\mathbf{1}$ & Introduce the aim(s) of a study & $\checkmark$ & $\checkmark$ & $\checkmark$ & $\checkmark$ \\
\hline $\mathbf{2}$ & Present the implications of a study & $\checkmark$ & $*$ & $\checkmark$ & $*$ \\
\hline $\mathbf{3}$ & Introduce the data used & $\checkmark$ & $*$ & $*$ & $*$ \\
\hline $\mathbf{4}$ & State the research questions & $*$ & $\checkmark$ & $*$ & $*$ \\
\hline $\mathbf{5}$ & State the significance of a study & $*$ & $*$ & $\checkmark$ & $*$ \\
\hline $\mathbf{6}$ & State the context of a study & $*$ & $*$ & $*$ & $\checkmark$ \\
\hline
\end{tabular}

Table 13: Discourse functions of introducing (part) of the study GS in RAIs

\subsection{Self-mention}

According to the results presented in Table 14, there is a noticeable disciplinary difference in terms of the application of self-mention in the four sets of RAIs. While the Psy writers dedicated the most GSs to the manifestation of self-mention ( 29 occurrences making up $7 \%$ of all GSs), the EE writers, on the other hand, showed little inclination towards its use (1\%). This indicates that the Psy writers favoured a more explicit presence in their research with an emphasis on showing their stance in relation to the arguments, community and reader (Harwood 2005). This finding might tell us that Psy writers, at least in this study, seek to be seen at the "cutting edge" of their field by using self-mentions (Berkenkotter \& Huckin 1995: 43). EE writers, on the other hand, seem to favour an approach that is more indirect, guiding readers to infer the authority behind the arguments and claims presented.

In relation to the discourse functions enacted using self-mention, the four sets of the RAIs were analysed and the results are plotted in Table 15. The only 
discourse function that was found in all four sets of RAIs was stating the study goal (Examples 50-53). In addition to clarifying the goal of the study explicitly, this can "align writers with their main position, giving a strong indication of where they stand in relation to the issue under discussion" (Hyland 2003: 15). Such deployment is yet another approach to the fulfilling of an obligatory goal in Swales' (1990) CARS model.

(50) In this paper we aim to investigate (1) to what extent $R A$ abstracts differ from $R A$ s with regard to the use of interpersonal elements, more specifically with the use of prominent interactional features as defined by Hyland (2005a), and (2) whether any changes have occurred in the past 30 years, since the use of $R A$ abstracts has become customary. (AL 6)

(51) Third, we examined the correlation between the indirect and the direct measure. (Psy 1)

(52) We also studied the hydrolytic degradation behavior of some of the polyesteramides. (Che 7)

(53) In the present study, we aim at establishing a detailed procedure to treat Al powder and to give reference treatment parameters to use in order to obtain the wanted oxide content. (EE 4$)$

Stating personal opinions and knowledge claims is a discourse function that was found in the AL, Psy and Che RAIs (Examples 54-56). This use of the selfmention GS indicates that these writers explicitly intended to take responsibility for their claims. Following Hyland (2001) and Tang and John (1999), this discourse function can help to convince the potential reader that the writer, along with their suggestions and claims, is worthy of attention. Using the self-mention GS to make a claim also helps to depict the researcher as an "Opinion-Holder" and "Originator" of new ideas (Tang \& John 1999: 28-29).

(54) We would expect the use of references to previous research to be an integral part of realizing this rhetorical function of master's thesis introductions. (AL 2)

(55) We expected more anxious children to show weaker associations between Control pictures and Me pictures than less anxious children on the Perceived Control IAP, as reflected in lower (or even negative) IAP scores. (Psy 1)

(56) We are inspired by the fact that when polymers are obtained in thermotropic liquid crystals they render oriented fibrillar networks. (Che 9)

With the exception of AL discipline, the self-mention GS was employed to report or summarise earlier findings (Examples 57-59). This employment 
could indicate the writers' disposition towards clearly situating their studies as a continuation of earlier studies. This result also shows that these three groups of writers presented their disagreement with or interest in earlier findings to imply their degree of confidence in presenting such disagreement or interest.

In a first study, we investigated the link between disgust sensitivity and spider phobia in a youth sample. (Psy 2)

(58) We have also reported some DFT results on the electronic structures and related properties of some Ru(II) polypyridyl complexes. (Che 2)

In a previous paper [37], we described for the first time, preparation of ultra filtration membranes by blending poly (acrylic acid) with uncharged polysulfone. (EE 3)

In AL, Psy and Che RAIs, the self-mention GS was also applied to elaborate on experimental procedures and methodology (Examples 60-62). Presenting information concerning how an experiment is to be carried out can build a picture of a study for the reader while she or he is still reading the RAI. Such information, in turn, can save the readers' time by helping them to decide whether to read the rest of the RA or not. This situation can also guide the readers throughout the steps of an experiment (Karahan 2013). The absence of such information in the EE RAIs could mean that those writers chose not to exercise this discourse function as it provides information that might be considered optional.

(60) In my analysis, I shall not include the first two types among backchannels, as their function is not to give feedback during someone else's turn, but rather to yield and claim the floor respectively. (AL 5)

(61) Second, we individualized the IAP, so the children could identify themselves more easily with the stimuli (see Section 2 for details). (Psy 1)

(62) With this purpose, we have synthesized hydrogels in media having anisotropic organization in the initial mixture. (Che 9)

AL and EE writers use the self-mention GS to create a research space (Examples 63-64). This discourse function helps to illustrate how a study is different from other studies conducted in the same area of investigation and if a study is worthy of attention (Swales 1990).

(63) We do not yet have sufficient indication of the variation between disciplines to decide this issue either way. (AL 3) 
(64) Thus, being a phenoxyacid herbicide, we need to further investigate the potential hepatotoxicity of 2,4-D. (EE 5)

Presenting a clear picture of the significance and uniqueness of an RA is a discourse function flagged up with the help of self-mention and this was found only in the AL RAIs (Example 65). This implication is that self-mention can enhance the chance of publication. As Gosden (1992: 129) puts it, writers need to convince editors, who are "looking for reason to reject RA", about the importance and significance of their study. To meet this need, AL writers in this study made use of self-mention explicitly to argue that their RAs were of value to the disciplinary community by presenting their work significance and uniqueness.

(65) Thus, as interactional metadiscourse is more directly and evidently related to interpersonality, we have restricted our research to this type. (AL 5)

Unique to AL RAIs, this GS was used to highlight the contribution of their study to the existing literature (Example 66). This discourse function emphasises the novelty of an RA to get past the gatekeepers of prestigious journals and get published.

In this way we hope to shed new light on the crystallization of RA abstracts as a separate, fully fledged genre in academic discourse, separate from the $R A$ and more specifically from the RA's introduction, out of which it has evolved. (AL 6)

The results show the greater inclination of soft science writers towards the use of self-mention compared to their counterparts in the hard sciences (Table 14). This finding indicates that writers in the soft sciences use self-mention to "gain credibility by projecting an identity invested with individual authority, displaying confidence in their evaluations and commitments to their ideas" (Hyland 2002: 1091).

\begin{tabular}{|c|c|c|c|c|}
\hline & \multicolumn{2}{|c|}{ Soft sciences } & \multicolumn{2}{c|}{ Hard sciences } \\
\hline & AL & Psy & Che & EE \\
\hline Self-mention & $26(6 \%)$ & $29(7 \%)$ & $14(5 \%)$ & $4(1 \%)$ \\
\hline
\end{tabular}

Table 14: Frequency and percentage of self-mention GS in RAIs 


\begin{tabular}{|c|l|c|c|c|c|}
\hline \multicolumn{1}{|c|}{ Discourse function } & AL & Psy & Che & EE \\
\hline $\mathbf{1}$ & Stating the goal of the study & $\checkmark$ & $\checkmark$ & $\checkmark$ & $\checkmark$ \\
\hline $\mathbf{2}$ & Stating personal opinions and knowledge claims & $\checkmark$ & $\checkmark$ & $\checkmark$ & $*$ \\
\hline $\mathbf{3}$ & Report or summarize earlier findings & $*$ & $\checkmark$ & $\checkmark$ & $\checkmark$ \\
\hline $\mathbf{4}$ & Elaborate on experimental procedures and methodology & $\checkmark$ & $\checkmark$ & $\checkmark$ & $*$ \\
\hline $\mathbf{5}$ & Create a research space & $\checkmark$ & $*$ & $*$ & $\checkmark$ \\
\hline $\mathbf{6}$ & $\begin{array}{l}\text { Present a clear picture of the significance and uniqueness } \\
\text { of an RA }\end{array}$ & $\checkmark$ & $*$ & $*$ & $*$ \\
\hline $\mathbf{7}$ & \begin{tabular}{l} 
Highlight the contribution to the existing literature \\
\hline
\end{tabular} & $\checkmark$ & $*$ & $*$ & $*$ \\
\hline
\end{tabular}

Table 15: Discourse functions of self-mention GS in RAIs

\section{Conclusion}

This study aimed to explore the use of GS types and the discourse functions served in the RAI across four disciplines, namely Chemistry and Environmental Engineering, representing the hard sciences, and Applied Linguistics and Psychology, representing the soft sciences.

From the procedures undertaken in GS analysis, a summary of the findings is presented to form the conclusion of the study. In the case of GS type selection in RAIs, the following conclusions were reached. The research-related object GS was the most dominant. This was employed to claim the centrality of a study in which it provided information on the importance and centrality of the topics under investigation. In relation to the frequency of GS types in the RAI section, the frequency of the personal citation GS could exemplify the disciplinary effect on the frequency of the selected GS types. These occurrences could be rooted in the nature of the disciplines. It is likely that the disciplinary rules and conventions have imposed on writers to use more of one type of GS according to the discipline. In the AL RAI section, writers preferred to use more of the personal citation GS to validate the information by situating well-known figures in the thematic position. Such an employment could help to guarantee the acceptance of the information by the disciplinary community members.

In relation to the discourse functions enacted by the use of the GS types in the RAI section, the discourse functions enacted by the use of the personal citation GS could clearly show the impact of the disciplinary conventions and rhetorical function of the RAI section on the discourse functions. The personal citation 
GS was used to serve three discourse functions. The first discourse function, presenting viewpoints and findings of earlier study by citing the authors, was imposed by the RAI section. In the RAI section, writers should include a review of the previous researches. The second discourse function, which was justifying the topic choice, was imposed by the nature of the science. As this discourse function was found only in the soft science disciplines, thus it could be justified based on the subjective nature of the studies in the soft science. The third discourse function was to define key terms by referring to literature. This discourse function was found only in Psy RAIs. This might be imposed by the nature of the discipline, as if the definition comes from a well-known figure in the community, then members in the community will agree easily.

\section{Implications}

The findings reported in this study may point to some implications for teaching RAI writing in English for Academic Purposes (EAP) courses. The findings of this study could clearly assist the textbooks developers to include information about how the GS is used and how it serves different discourse functions in RAIs. In addition, the findings reported in this study stress that writing is restricted by the disciplinary conventions. Therefore, EAP instructors who run RAI writing courses need to inform learners about how discourse functions enacted by employment of different GSs are restricted by the disciplinary conventions. This could enable learners to make more conscious selections of GSs to serve the discourse function.

\section{References}

Becher, T. (1989) Academic Tribes and Territories: Intellectual Enquiry and the Cultures of Disciplines. Milton Keynes: Open University Press.

Becher, T. (1994) 'The significance of disciplinary differences.' Studies in Higher Education, 19/2, 151-161.

Becher, T. and Trowler, P. R. (2001) Academic Tribes and Territories. Milton Keynes: Open University Press.

Berkenkotter, C. and Huckin, T. N. (1995) Genre Knowledge in Disciplinary Communication: Cognition/Culture/Power. Hillsdale: Lawrence Erlbaum Associates.

Bloor, T. and Bloor, M. (1995) The Functional Analysis of English: A Hallidayan Approach. London: Arnold.

del Saz Rubio, M. M. (2011) 'A pragmatic approach to the macro-structure and metadiscoursal features of research article introductions in the field of Agricultural Sciences.' English for Specific Purposes, 30/4, 258-271.

Ebrahimi, S. F. (2014) Thematicity in English Academic Research Articles across Disciplines in Hard and Soft Sciences. Unpublished doctoral thesis, UPM, Malaysia. 
Ebrahimi, S. F. and Chan, S. H. (2015) 'Research article abstracts in applied linguistics and economics: Functional analysis of the grammatical subject.' Australian Journal of Linguistics, 35/4, 381-397.

Fakhri, A. (2004) 'Rhetorical properties of Arabic research article introductions.' Journal of Pragmatics, 36/6, 1119-1138.

Gledhill, C. (2000) 'The discourse function of collocation in research article introductions.' English for Specific Purposes, 19/2, 115-135.

Ghadessy, M. (1999) 'Thematic organization in academic articles abstracts.' Estudios Ingleses de la Universidad Complutense, 7, 141-161.

Gosden, H. (1992) 'Discourse functions of marked theme in scientific research articles.' Journal of English for Specific Purposes, 11/3, 207-224.

Gosden, H. (1993) 'Discourse functions of subject in scientific research articles.' Applied Linguistics, 14/1, 56-75.

Harwood, N. (2005) 'Nowhere has anyone attempted... In this article I aim to do just that: A corpus-based study of self-promotional I and we in academic writing across four disciplines.' Journal of Pragmatics, 37/8, 1207-1231.

Hasselgard, H., Johansson, S. and Lysvag, P. (1998) English Grammar: Theory and Use. Oslo: Universitetsforlaget.

Hewings, M. and Hewings, A. (2002) "“It is interesting to note that...": a comparative study of anticipatory 'it' in student and published writing.' English for Specific Purposes, 21/4, 367-383.

Hewings, A., Lillis, T. and Vladimirou, D. (2010) 'Who's citing whose writings? A corpus based study of citations as interpersonal resource in English medium national and English medium international journals.' Journal of English for Academic purposes, 9/2, 102-115.

Hirano, E. (2009) 'Research article introductions in English for specific purposes: A comparison between Brazilian Portuguese and English.' English for Specific Purposes, 28/4, 240-250.

Hunston, S. and Sinclair, J. (2000) 'A local grammar of evaluation.' In: Hunston, S. and Thompson, G. (eds) Evaluation in Text: Authorial Stance and the Construction of Discourse. Oxford: Oxford University Press. 74-101.

Hyland, K. (1999) 'Academic attribution: Citation and the construction of disciplinary knowledge.' Applied Linguistics, 20/3, 341-367.

Hyland, K. (2001) 'Humble servants of the discipline? Self-mention in research articles.' English for Specific Purposes, 20/3, 207-226.

Hyland, K. (2002) 'Authority and invisibility: Authorial identity in academic writing.' Journal of pragmatics, 34/8, 1091-1112.

Hyland, K. (2003) Second Language Writing. New York: Cambridge University Press.

Hyland, K. (2009) 'Writing in the disciplines: Research evidence for specificity.' Taiwan International ESP Journal, 1/1, 5-22.

Jalilifar, A. R. (2009) Research Article in Applied Linguistics: A Gender-Based Writing Guide. Ahwaz: Shahid Chamran University Press.

Karahan, P. (2013) 'Self-mention in scientific articles written by Turkish and non-Turkish Authors.' Procedia-Social and Behavioral Sciences, 70, 305-322.

Lim, J. M. H. (2012) 'How do writers establish research niches? Agenre-based investigation into management researchers' rhetorical steps and linguistic mechanisms.' Journal of English for Academic Purposes, 11/3, 229-245. 
Loi, C. K. and Evans, M. S. (2010) 'Cultural differences in the organization of research article introductions from the field of educational psychology: English and Chinese.' Journal of Pragmatics, 42/10, 2814-2825.

Martín, P. and Pérez, I. K. L. (2014) 'Convincing peers of the value of one's research: A genre analysis of rhetorical promotion in academic texts.' English for Specific Purposes, 34, 1-13.

Ozturk, I. (2007) 'The textual organisation of research article introductions in applied linguistics: Variability within a single discipline.' English for Specific Purposes, 26/1, 25-38.

Petrić, B. and Harwood, N. (2013) 'Task requirements, task representation, and selfreported citation functions: An exploratory study of a successful L2 student's writing.' Journal of English for Academic Purposes, 12, 110-124.

Saadabadi, H. and Ebrahimi, S. F. (2014) "This study tests....." Functional analysis of the grammatical subjects in research article abstracts: A cross disciplinary study.' International Journal of English Language and Literature Studies, 3/4, 341-349.

Samraj, B. (2002) 'Introductions in research articles: Variations across disciplines.' English for Specific Purposes, 21/1, 1-17.

Sheldon, E. (2011) 'Rhetorical differences in RA introductions written by English L1 and L2 and Castilian Spanish L1 writers.' Journal of English for Academic Purposes, 10/4, 238-251.

Swales, J. M. (1990) Genre Analysis: English in Academic and Research Setting. Cambridge: Cambridge University Press.

Tang, R. and John, S. (1999) 'The ' $I$ ' in identity: Exploring writer identity in student academic writing through the first person pronoun.' English for Specific Purposes, $18,23-39$.

Thompson, G. (1994) Collins COBUILD English Guides 5: Reporting. London: Harper Collins.

Seyed Foad Ebrahimi is Assistant Professor at Islamic Azad University, Shadegan branch. He is interested in discourse analysis studies, especially studies on systemic functional analysis. His main areas of research are text analysis and discourse studies. He has published more than 30 papers and participated in more than 14 international conferences.

Address: Seyed Foad Ebrahimi, Ph.D., Department of English, Shadegan Branch, Islamic Azad University, Shadegan, Iran. PH: 00989168853083. [e-mail: seyedfoade@gmail.com] 